\title{
Computation of Natural Convection in Channels With Pin Fins
}

\author{
Dhanunjay S. Boyalakuntla, Jayathi Y. Murthy, and Cristina H. Amon, Fellow, IEEE
}

\begin{abstract}
In this paper, we numerically analyze the possibility of using buoyant flow in the display panel of a laptop for electronics cooling. Three-dimensional (3-D) channels with embedded pin fin arrays are analyzed using an unstructured finite volume method. Studies have been performed with a uniform heat flux boundary condition applied on the inner wall as well as for a constant inner wall temperature condition; the outer wall in all cases is exposed to the ambient. A single periodic module is selected in the lateral direction. In the axial mean flow direction, however, the entire height of the display channel is considered. Buoyancy has been modeled using Boussinesq approximation. A range of Rayleigh numbers, panel inclinations, and pin fin arrangements are considered. Local and global flow and heat transfer results are obtained including Nusselt numbers as well as local temperature and velocity fields. The results are useful in designing augmented cooling schemes in portable electronics.
\end{abstract}

Index Terms-Channel inclination, channels, chimney, electronics cooling, natural convection, numerical, Nusselt number, pin fin spacing, pin fins, Rayleigh number.

\section{NOMENCLATURE}

a

A

b

c

$c_{p}$

d

D

E

$\mathrm{F}$

$\mathrm{H}$

k

$\mathrm{k}_{\mathrm{S}}$

g

L

$\mathrm{m}$

M

$\mathrm{Nu}$
$\mathrm{Nu}_{\mathrm{m}}$

$\mathrm{p}$

$p_{0}$

$\mathrm{P}$

$\mathrm{Pr}$

$q$

$\mathrm{Ra}_{\mathrm{q}}$

$\operatorname{Ra}_{\mathrm{T}}$

$\mathrm{S}_{\mathrm{X}}$

$\mathrm{S}_{\mathrm{y}}$

$\mathrm{S}_{\mathrm{z}}$

$\mathrm{T}$

$\mathrm{u}, \mathrm{v}, \mathrm{w}$

$\mathrm{U}, \mathrm{V}, \mathrm{W}$

$\mathrm{x}, \mathrm{y}, \mathrm{z}$

$\mathrm{X}, \mathrm{Y}, \mathrm{Z}$
Mean Nusselt Number.

Local static pressure.

Reference pressure.

Dimensionless pressure.

Prandtl Number.

Applied heat flux.

Rayleigh number for constant inner wall heat flux condition.

Rayleigh number for constant inner wall temperature condition.

Horizontal center to center spacing between fins.

Vertical center to center distance between fins.

Fin length.

Temperature.

Velocities in $\mathrm{x}, \mathrm{y}, \mathrm{z}$ direction.

Dimensionless velocities.

Axis of rectangular coordinate system.

Dimensionless coordinates.

\section{Greek Symbols}

Thermal diffusivity.

Coefficient of thermal expansion.

Dimensionless temperature.

Dynamic viscosity.

Kinematic viscosity.

Re-normalized temperature.

Panel inclination (angle measured from vertical).

Density.

Channel width nondimensionalized with the $\rho$

chimney length.

Pin fin diameter nondimensionalized with the

chimney length.

Display panel width.

Fluid thermal conductivity.

Solid thermal conductivity.

Acceleration due to gravity.

Chimney length (display height).

Mass flow rate.

Dimensionless mass flow rate $\left(\mathrm{m} /\left(\mathrm{kd} / \mathrm{c}_{\mathrm{p}}\right)\right)$.

Local Nusselt Number.

Manuscript received November 16, 2001; revised February 4, 2003. This work was recommended for publication by Associate Editor P. Sathyamurthy upon evaluation of the reviewers' comments. This work was supported in part by DARPA's HERETIC Program and Fluent Inc.

D. S. Boyalakuntla and C. H. Amon are with the Department of Mechanical Engineering, Carnegie Mellon University, Pittsburgh, PA 15213 USA (e-mail: dboya@andrew.cmu.edu; camon@andrew.cmu.edu).

J. Y. Murthy is with the Department of Mechanical Engineering, Purdue University, West Lafayette, IN 47907 USA (e-mail: jmurthy@ecn.purdue.edu).

Digital Object Identifier 10.1109/TCAPT.2004.825751

\section{Subscripts}

Inlet.

Mean.

Constant heat flux condition.

Constant temperature condition.

Wall.

Wall mean.

\section{INTRODUCTION}

$\mathbf{I}$ $\mathrm{N}$ RECENT years, a rapid increase in the chip speed of laptop and portable electronic devices has led to a large increase in device heat loads. For portables, the lack of sufficient device surface area means that all surfaces must be utilized optimally to achieve cooling. For a typical laptop, it may be possible to use the back of the display panel as a chimney to draw ambient air and dissipate heat. Employing pin fins embedded in the chimney not only augments surface area, but also the drawing power of the chimney. In this paper, a study is performed to understand the limits of free convection for this arrangement 
and to determine the optimal fin geometry to maximize thermal performance.

Peterson and Ortega [19] have reviewed the use of natural convection, among other approaches, to cooling electronic equipment. A number of analytical and numerical studies of developing and fully-developed flow between vertical flat plates are available [2]-[6]. Buoyancy driven flow due to wall-mounted heat sources have been studied both experimentally and numerically by Jaluria et al. [9], [10]. Ortega and Moffat [16], [17] published experimental measurements of natural convection due to wall-mounted cubical elements.

A variety of studies have examined pin fins in forced flow. Square-fin array experiments in forced flow in the low Reynolds $\left(\sim 10^{2}\right)$ regime have been conducted by Shaukatullah et al. [21]. An optimal porosity of $92 \%$ was obtained for an in-line pin-fin arrangement. Armstrong and Winstanley [1] studied heat transfer from staggered array of pin-fins for forced flow Reynolds number (based on fin diameter) greater than $10^{3}$. Jubran et al. [11] reported experimental results for in-line and staggered pin-fin arrays for forced flow Reynolds number of about $10^{4}$. An optimal porosity of $87 \%$ was obtained for both types of arrays. Zografos and Sunderland [22] experimentally found an optimal porosity of $90 \%$ among four heat sinks with porosities in the range of 60 to $90 \%$. An analytical study was performed on a pin-fin heat sink in a chimney by Fisher et al. [7]. The problem was simplified as two-dimensional (2-D) and optimal values of the pin-fin diameter and porosity were found for maximum heat transfer as a function of Rayleigh number.

Nearly all published computational results are 2-D. Karki and Patankar [12] published a parabolic marching solution for chimney flow in a shrouded plate fin array. Since no recirculations were expected, results could be obtained at relatively low cost by solving a 2-D problem in the cross-section and marching axially. Kelkar and Choudhury [13] computed 2-D buoyancy driven flow in a periodically fully-developed flow regime in a vertical channel with periodically mounted heat generating blocks; the assumption of periodicity allowed them to limit problem size.

This paper considers the use of pin-fin arrays in vertical and inclined channels for cooling electronics using the chimney effect. Though there are numerous studies of buoyant convection in channels both vertical and inclined, we are unaware of any involving developing buoyant convection in channels with surface enhancements such as pin fins. In these cases, the flow is fully three-dimensional (3-D) and elliptic, and no marching solutions are possible because of recirculations on the trailing edges of the fins. Periodicity between modules in the flow direction cannot be invoked because realistic thermal boundary conditions do not typically support thermal periodicity. As a result, the entire channel length must be considered in the computational domain. In a previous study [8] we computed buoyancy-driven flow in vertical and inclined channels with in-line pin fins with constant heat flux boundary conditions. It was found that though an optimum placement in the horizontal spacing could be found, the Nusselt number increased continuously as the vertical fin spacing was reduced. The present paper completes the study by considering pin fins in a staggered arrangement with both constant heat flux and constant temperature boundary conditions.

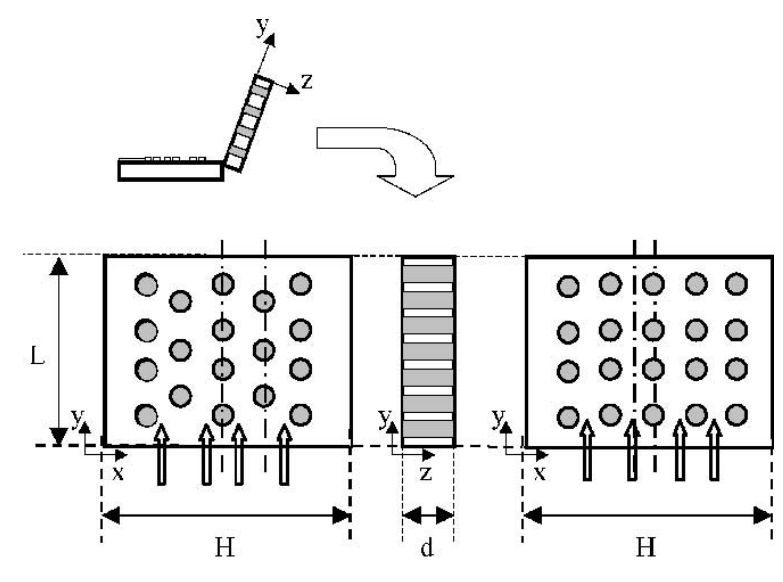

(a)

(b)

Fig. 1. Physical configuration (a) staggered pin fin array (b) in-line pin fin array.

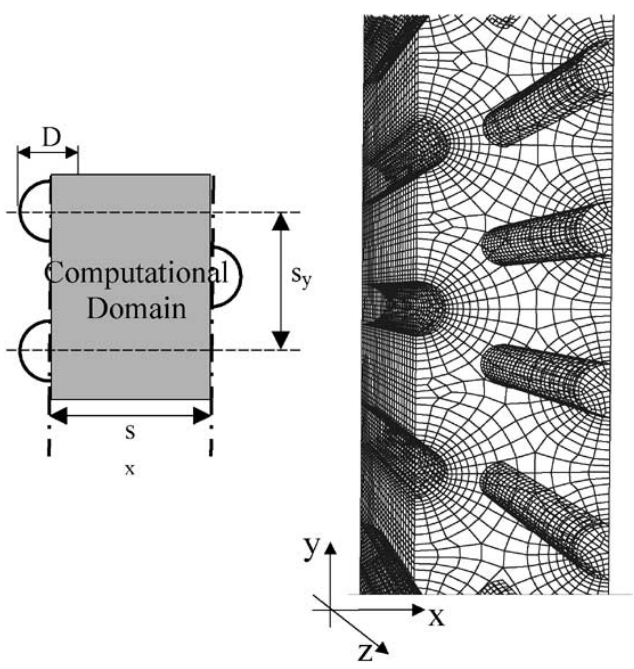

Fig. 2. Local staggered pin fin geometry and a portion of the computational domain.

\section{PROBLEM Description}

The geometry considered is shown in Fig. 1. Buoyancy-driven flow cools the back of the display panel of a laptop computer due to the chimney effect. The flow is assumed symmetric around the pin fins in the lateral (z) direction and periodic in adjacent columns of fins. Therefore, a single periodic module is selected. In the axial (y) direction, the entire height of the display panel is considered.

The detailed pin fin geometry is shown in Figs. 1 and 2. A staggered pin fin arrangement is considered. The pin diameter is $\mathrm{D} ; \mathrm{s}_{\mathrm{x}}$ and $\mathrm{s}_{\mathrm{y}}$ are the horizontal and vertical center-to-center spacing between the fins. The fins have a length $\mathrm{s}_{\mathrm{z}}$, which is also the depth of the channel d. Other geometric parameters include $\mathrm{L}$, the height of the laptop back panel, and $\mathrm{H}$, its width.

\section{GOVERNING EQUATIONS}

The flow field is considered laminar, 3-D, incompressible, Newtonian and steady. All fluid properties are assumed uniform except for density in the buoyancy term, which is modeled using the Boussinesq approximation. Radiation effects are neglected 
because the temperature levels involved are close to ambient. The governing equations are nondimensionalized using the following dimensionless variables:

$$
\begin{aligned}
& X=\frac{x}{L} ; \quad Y=\frac{y}{L} ; \quad Z=\frac{z}{L} ; \quad U=\frac{u L}{\alpha} ; \quad V=\frac{v L}{\alpha} \\
& W=\frac{w L}{\alpha} ; \quad P=\frac{\left(p-p_{0}\right) L^{2}}{\rho \alpha^{2}} ; \quad \theta=\frac{T-T_{i}}{\Delta T}
\end{aligned}
$$

with

$$
\begin{aligned}
& \Delta T=\frac{q d}{k} \quad \text { for constant heat flux conditions } \\
& \quad \text { on innerwall } \\
& \Delta T=T_{w}-T_{i} \quad \text { for constant temperature conditions } \\
& \quad \text { on innerwall. }
\end{aligned}
$$

Here $T_{i}$ is the ambient temperature, $\rho$ is the reference density, and the reference pressure $\mathrm{p}_{0}$ is given by

$$
p_{0}=-\rho g(y \cos \psi-z \sin \psi)
$$

where $\psi$ is the angle between the gravity vector and the negative $\mathrm{y}$ direction. The dimensionless governing equations are given by the following.

Continuity: $\nabla \cdot \mathbf{V}=0$.

X-Momentum: $\nabla \cdot(\mathbf{V} U)=-(\partial P / \partial X)+\nabla^{2} U$.

Y-Momentum: $\nabla \cdot(\mathbf{V} V)=-(\partial P / \partial Y)+\nabla^{2} V+$ $R a \operatorname{Pr} \theta \cos \psi$.

Z-Momentum: $\nabla \cdot(\mathbf{V} W)=-(\partial P / \partial Z)+\nabla^{2} W-$

$R a \operatorname{Pr} \theta \sin \psi$.

Energy: $\nabla \cdot(\mathbf{V} \theta)=\nabla^{2} \theta$ (Fluid).

$$
\nabla^{2} \theta=0 \text { (Solid) }
$$

Here, the gravity vector is given by

$$
\mathbf{g}=-g \cos \psi \mathbf{j}+g \sin \psi \mathbf{k}
$$

where $\mathrm{g}$ is the acceleration due to gravity.

\section{BOUNDARY CONDITIONS}

The computational domain chosen is shown in Fig. 1. Symmetry boundary conditions are applied on the $\mathrm{X}=0$ and $\mathrm{X}=$ $\mathrm{s}_{\mathrm{X}} / \mathrm{L}$ boundaries. Either a constant heat flux condition or a constant temperature condition is applied on the inner wall $\mathrm{Z}=0$, and a convective heat transfer condition at $\mathrm{Z}=\mathrm{s}_{\mathrm{z}} / \mathrm{L}$. At the channel inlet, the stagnation pressure is set to the reference pressure $\mathrm{p}_{0}$, as is the static pressure at the exit. This is equivalent to setting the inlet and exit pressure equal to the hydrostatic pressure of the fluid outside the channel. These boundary conditions may be written as

$$
\begin{aligned}
& \mathrm{X}=0 \text { and } \mathrm{X}=\mathrm{s}_{\mathrm{x}} / \mathrm{L} \text { Boundary } \\
& \qquad U=0 ; \quad \frac{\partial V}{\partial X}=\frac{\partial W}{\partial X}=\frac{\partial \theta}{\partial X}=0 . \\
& \mathrm{Y}=0 \text { Boundary }
\end{aligned}
$$

$$
P=0 ; \quad \theta=0 \text {. }
$$

$\mathrm{Y}=1$ Boundary

$$
P=0 ; \quad \frac{\partial \theta}{\partial Y}=0 .
$$

$\mathrm{Z}=0$ Boundary

$$
U=V=W=0
$$

For the portion of the boundary in contact with the fluid

$$
\begin{gathered}
\frac{\partial \theta}{\partial Z}=-\left(\frac{L}{d}\right) \quad \begin{array}{r}
\text { for constant heat flux } \\
\text { boundary conditions }
\end{array} \\
\theta=1 \quad \text { for constant temperature } \\
\text { boundary conditions. }
\end{gathered}
$$

For the portion of the boundary in contact with the solid

$$
\begin{aligned}
& \frac{k_{s}}{k} \frac{\partial \theta}{\partial Z}=-\left(\frac{L}{d}\right) \quad \begin{array}{r}
\text { for constant heat flux } \\
\text { boundary conditions }
\end{array} \\
& \theta=1 \quad \text { for constant temperature } \\
& \text { boundary conditions }
\end{aligned}
$$

$$
\mathrm{Z}=\mathrm{s}_{\mathrm{z}} / \mathrm{L} \text { Boundary }
$$

$$
U=V=W=0
$$

For the portion of the boundary in contact with the fluid

$$
\frac{\partial \theta}{\partial Z}=-N u_{e}\left(\frac{L}{D}\right) \theta .
$$

For the portion of the boundary in contact with the solid

$$
\frac{k_{s}}{k} \frac{\partial \theta}{\partial Z}=-N u_{e}\left(\frac{L}{D}\right) \theta .
$$

Conjugate heat transfer between the fin and the surrounding air is considered. There is no conduction along the channel wall in the axial (y) direction.

\section{NON-DIMENSIONAL PARAMETERS}

The nondimensional parameters governing the problem are the Rayleigh number Ra, the Prandtl number Pr, the Nusselt number of the external convective flow $\mathrm{Nu}_{\mathrm{e}}$, the channel inclination $\psi$, the conductivity ratio $\mathrm{k}_{\mathrm{s}} / \mathrm{k}$, and various geometric parameters. These are defined as

$$
\begin{aligned}
R a & =\frac{g \beta \Delta T L^{3}}{\nu \alpha} ; \quad \operatorname{Pr}=\frac{\nu}{\alpha} ; \quad N u_{e}=\frac{h D}{k} \\
a & =\frac{s_{x}}{D} ; \quad b=\frac{s_{y}}{D} ; \quad c=\frac{s_{z}}{D} ; \quad E=\frac{d}{L} ; \\
F & =\frac{D}{L} ; \quad A=\frac{H}{L} .
\end{aligned}
$$

For convenience, we further define

$$
\begin{aligned}
R a_{q} & =\frac{g \beta\left(\frac{q d}{k}\right) L^{3}}{\nu \alpha} \\
R a_{T} & =\frac{g \beta\left(T_{w}-T_{i}\right) L^{3}}{\nu \alpha} .
\end{aligned}
$$




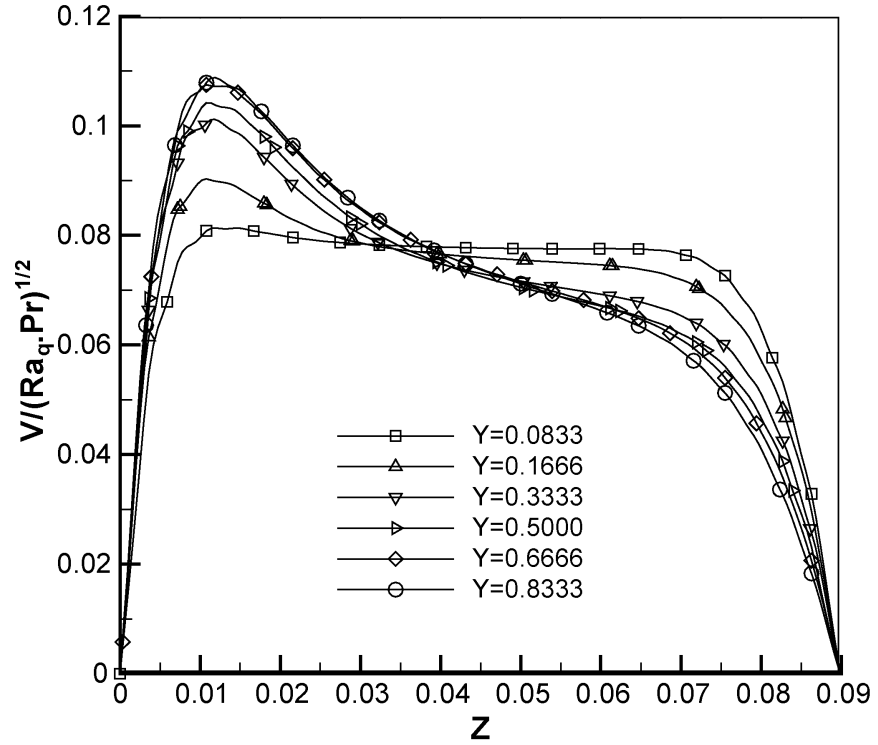

Fig. 3. Velocity profile along the width of channel for the baseline case for the staggered pin fin array with constant inner wall heat flux and $\mathrm{Ra}_{\mathrm{q}}=10^{9}$ at $\mathrm{X}=0.0135\left(\mathrm{x} / \mathrm{s}_{\mathrm{x}}=0.5\right)$.

\section{NUMERICAL METHOD}

The unstructured finite volume method described in Mathur and Murthy [14] is used. The calculation domain is divided to arbitrary unstructured polyhedral control volumes over which balances of mass, momentum and energy are written [15]. A co-located cell-centered formulation is used. A second-order upwind scheme is used for both the momentum and energy equations. Gradients are computed using linear reconstruction. For fluid flow, a sequential pressure-based algorithm, SIMPLE [18], is used. An added-dissipation scheme similar to that of Rhie and Chow [20] is used to prevent checker-boarding. The flow and energy equations are solved sequentially, using Picard iteration for nonlinearity and coupling. The nominally linear algebraic equations resulting from the discretization of each governing equation are solved using an algebraic multigrid method. This method is the basis of the commercial solver FLUENT, which is used in this paper.

\section{RESULTS AND DISCUSSION}

\section{A. Computational Parameters}

In Fig. 3, the dimensionless vertical velocity $\mathrm{V}$ is plotted versus the cross-sectional coordinate along the fin, $\mathrm{Z}$, at $\mathrm{X}=$ $0.0135\left(\mathrm{x} / \mathrm{s}_{\mathrm{x}}=0.5\right)$ for different $\mathrm{Y}$ locations in the channel for the give-flux case. The Y locations are chosen to lie half-way between adjacent fins in the axial direction, and are equidistant from each other. The Rayleigh number is $\mathrm{Ra}_{\mathrm{q}}=10^{9}$. The initial velocity profile is nearly a plug-flow profile, but develops a peak at the hot wall due to buoyancy. The corresponding temperature profiles are plotted in Fig. 4. The profiles develop as the flow passes through the channel, with boundary layers at the hot and cold walls. In Fig. 4, we see that the temperature profiles in the fluid do not collapse upon each other but achieve approximate self-similarity; As a result, the velocity profiles at $\mathrm{Y}=0.666$ and 0.833 nearly collapse upon each other in Fig. 3, suggesting that near-periodicity in $\left(\mathrm{T}-\mathrm{T}_{\mathrm{w}}\right)$ has been achieved.

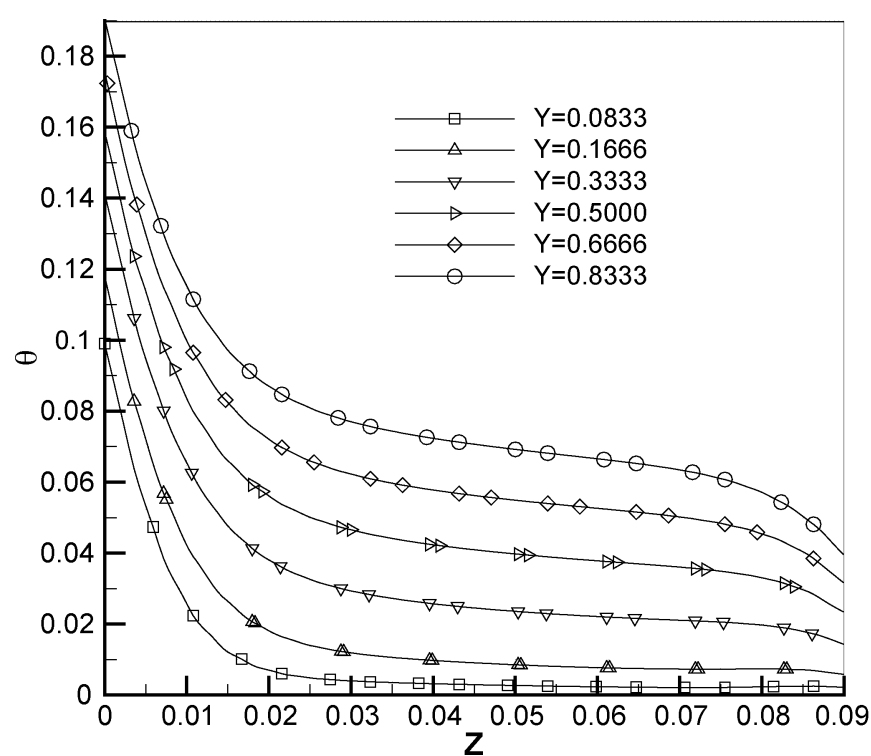

Fig. 4. Dimensionless temperature distribution in fluid along the width of channel for the baseline case for the staggered pin fin array with constant inner wall heat flux and $\mathrm{Ra}_{\mathrm{q}}=10^{9}$ at $\mathrm{X}=0.0135\left(\mathrm{x} / \mathrm{s}_{\mathrm{x}}=0.5\right)$.

The parameters used are the same as in Jain et al. [8] except that adjacent rows of pin fins are displaced by $s_{y} / 2$ in the $y$ direction. The display panel is assumed to have dimensions $\mathrm{H} \times \mathrm{L}$ of $0.3454 \mathrm{~m} \times 0.2225 \mathrm{~m}$. A total heat transfer rate of $78 \mathrm{~W}$ is assumed to dissipate over the back panel, leading to an inner-wall heat flux of $1020 \mathrm{~W} / \mathrm{m}^{2}$. The ambient temperature is assumed to be $285 \mathrm{~K}$ and heat transfer coefficient at the outer wall is $7.5 \mathrm{~W} / \mathrm{m}^{2}-\mathrm{K}$, which is typical of natural convection for a vertically heated plate.

The length of fin $\mathrm{s}_{\mathrm{z}}$, which is also the depth of the chimney, is assumed to be $2 \mathrm{~cm}$. This parameter is not changed in this paper. The nominal diameter of the fin is assumed to be $2 \mathrm{~mm}$. The nominal vertical and horizontal spacing, $\mathrm{s}_{\mathrm{y}}$ and $\mathrm{s}_{\mathrm{x}}$, are chosen to be $6 \mathrm{~mm}$ each. Using these dimensions and operating parameters as a basis, the following dimensionless parameters are chosen. The Rayleigh number is varied from $10^{5}$ to $10^{9}$ for both types of inner wall boundary conditions. The Prandtl number is fixed at 0.7 . The external Nusselt number $\mathrm{Nu}_{\mathrm{e}}$ is fixed at 0.62 . The parameter a $\left(=\mathrm{s}_{\mathrm{x}} / \mathrm{D}\right)$ is varied from 2.0 to 6.0 . The parameter $\mathrm{b}\left(=\mathrm{s}_{\mathrm{y}} / \mathrm{D}\right)$ is varied from 1.5 to 4.0 . The parameter $\mathrm{c}\left(=\mathrm{s}_{\mathrm{z}} / \mathrm{D}\right)$ is held at 10. The fin length and the fin diameter are assumed constant in the calculations done here; thus $\mathrm{E}=0.09$ and $\mathrm{F}=$ 0.009 are used throughout. The ratio of thermal conductivity of solid to gas is assumed to be 200 .

Studies of mesh size dependency have been done previously by Jain et al. [8] for an in-line pin fin array and indicate that the overall Nusselt number and mass flow rate are accurate to approximately $1 \%$ with a mesh of approximately 200000 cells. In this study we employ a 300000 cell mesh for all computations.

\section{B. Flow Regimes}

In general, a buoyancy-driven flow can achieve a fully-developed or periodic state only if both the velocity and temperature fields achieve periodicity between axial modules. However, we are not generally interested in fully-developed regimes in which the temperature itself becomes periodic because the bulk tem- 


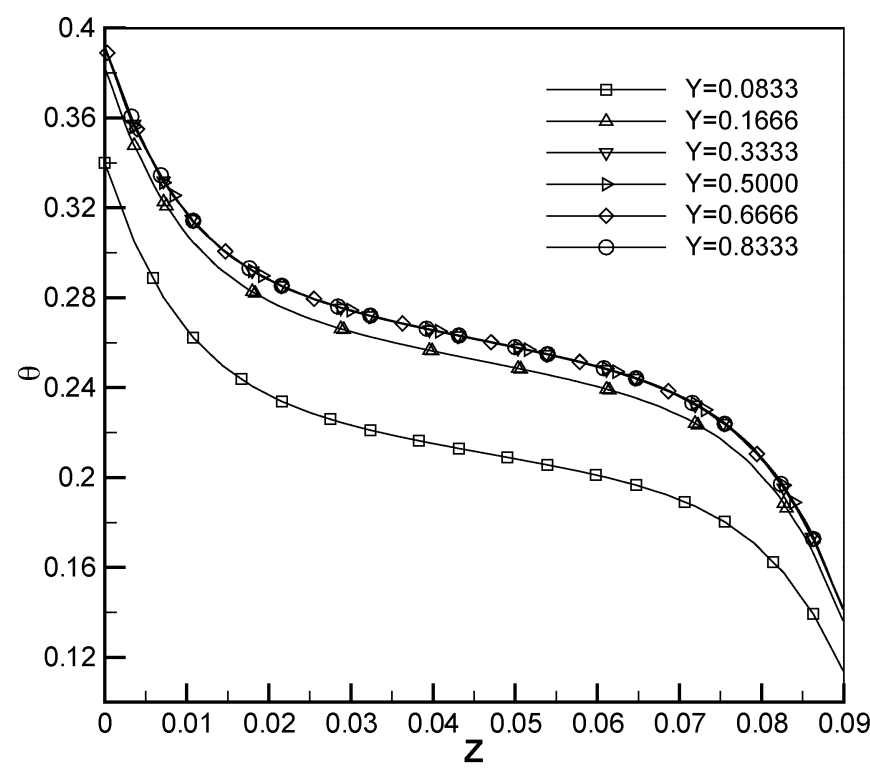

Fig. 5. Dimensionless temperature distribution in fluid along the width of channel for the baseline case for the staggered pin fin array with constant inner wall heat flux and $\mathrm{Ra}_{\mathrm{q}}=10^{5}$ at $\mathrm{X}=0.0135\left(\mathrm{x} / \mathrm{s}_{\mathrm{x}}=0.5\right)$.

perature becomes constant and no net heat transfer to the fluid takes place.

Fig. 5 shows the same plot at $\operatorname{Ra}_{\mathrm{q}}=10^{5}$. Here we see that the temperature profiles do indeed collapse on each other at location farther up the channel; i.e. T itself becomes periodic. This is illustrated more fully in Figs. 6 and 7 which re-plot Figs. 4 and 5 in terms of the re-normalized temperature $\phi=\left(\mathrm{T}_{\mathrm{w}}-\right.$ $\mathrm{T}) /(\mathrm{qd} / \mathrm{k})$. Here $\mathrm{T}_{\mathrm{w}}$ is the temperature on the hot wall at the axial location of interest. Also added are plots of the temperature variation along the axis of the pin fin. For high $\mathrm{Ra}_{\mathrm{q}}$ (Fig. 6), we see that the temperature profiles in the fluid collapse together except for locations near the cold wall, indicating near-self similarity. In Fig. 7, for $\mathrm{Ra}_{\mathrm{q}}=10^{5}$, since $\mathrm{T}$ is self-similar farther up the channel, the re-normalized temperature $\left(\mathrm{T}_{\mathrm{w}}-\mathrm{T}\right) /(\mathrm{qd} / \mathrm{k})$ is also self-similar. For this low value of $\mathrm{Ra}_{\mathrm{q}}$, no net heat transfer to the fluid takes place beyond $\mathrm{Y}=0.333$.

Let us first consider constant heat flux boundary conditions on the inner wall. For clarity, let us assume that the outer wall is adiabatic, and let us consider a periodic module in the axial (y) direction. The buoyancy term in the momentum equation for a vertical channel is given by

$$
\frac{R a \operatorname{Pr}\left(T-T_{i}\right)}{\left(\frac{q d}{k}\right)}=\frac{R a \operatorname{Pr}\left(T-T_{w}\right)}{\left(\frac{q d}{k}\right)}+\frac{R a \operatorname{Pr}\left(T_{w}-T_{i}\right)}{\left(\frac{q d}{k}\right)}
$$

where $T_{\mathrm{w}}$ is a representative wall temperature in the module. The second term on the RHS is only a function of $\mathrm{Y}$ and can be absorbed into the Y-direction pressure gradient term. Since $\left(\mathrm{T}-\mathrm{T}_{\mathrm{w}}\right)$ becomes constant between modules for given-flux boundary conditions, the flow and $\theta$ fields become periodic. In this limit, the bulk temperature $\mathrm{T}_{\mathrm{b}}$ increases linearly from module to module in the axial direction and net heat transfer to the fluid occurs.

For the constant heat flux boundary condition considered here, this type of periodicity is not possible because the outer wall is not adiabatic, but has a convective boundary condition

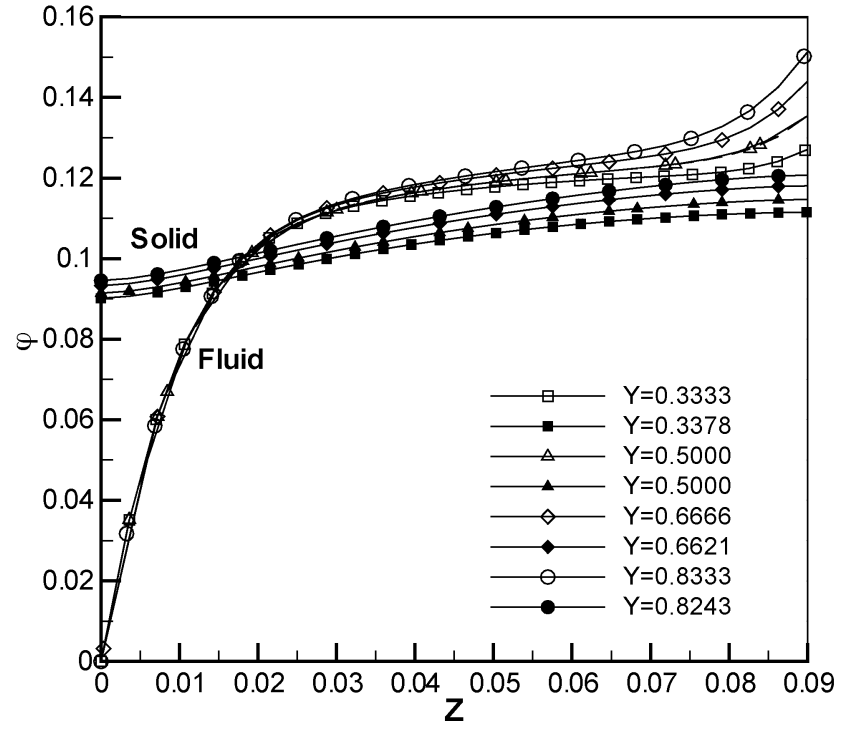

Fig. 6. Renormalized temperature distribution along the width of channel for the baseline case for the staggered pin fin array with constant inner wall heat flux and $\mathrm{Ra}_{\mathrm{q}}=10^{9}$. For fluid the data is shown at $\mathrm{X}=0.0135$. For fins the data is shown along the pin-fin centerline at $\mathrm{X}=0.027$.

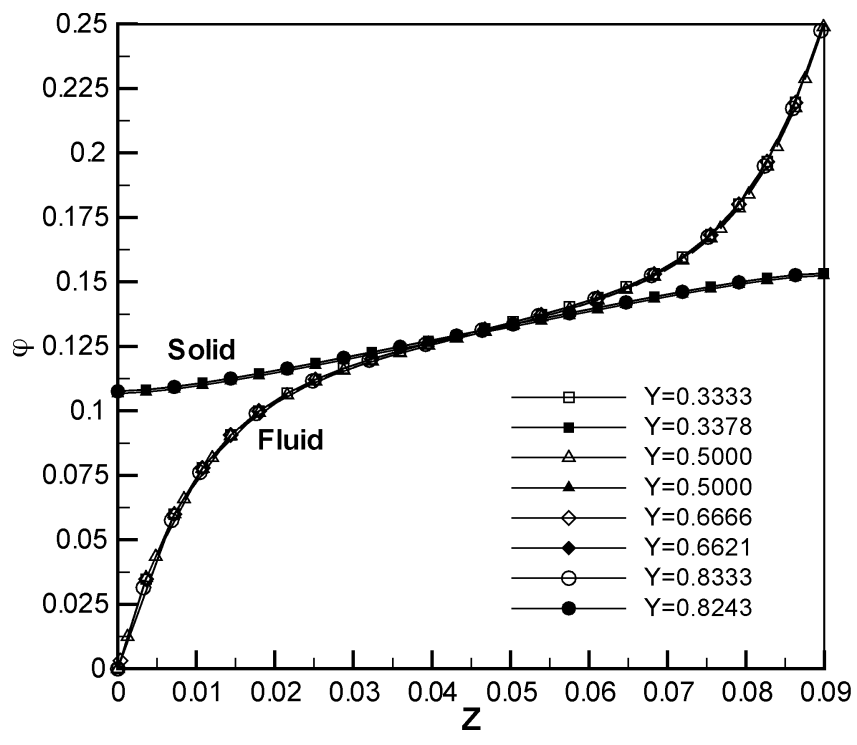

Fig. 7. Renormalized temperature distribution along the width of channel for the baseline case for the staggered pin fin array with constant inner wall heat flux and $\mathrm{Ra}_{\mathrm{q}}=10^{5}$. For fluid the data is shown at $\mathrm{X}=0.0135$. For fins the data is shown along the pin-fin centerline at $\mathrm{X}=0.027$.

imposed. Strictly speaking, the only type of periodic flow that is possible is that flow and temperature become periodic with the bulk temperature $\mathrm{T}_{\mathrm{b}}$ becoming constant from module to module. Unlike fully-developed duct flow however, secondary flow in the module is present even when periodicity is achieved. In this limit, all heat supplied at the hot wall is transported to the cold wall by conduction and the local secondary flow. When $\mathrm{Nu}_{e}$ is small but not zero, the flow develops from the inlet condition to a condition where approximate periodicity in $\left(\mathrm{T}-\mathrm{T}_{\mathrm{w}}\right)$ is exhibited, and ultimately to a condition where $\mathrm{T}$ itself becomes periodic.

This type of periodicity is not possible for given-temperature boundary conditions, or for any other mixture of boundary con- 


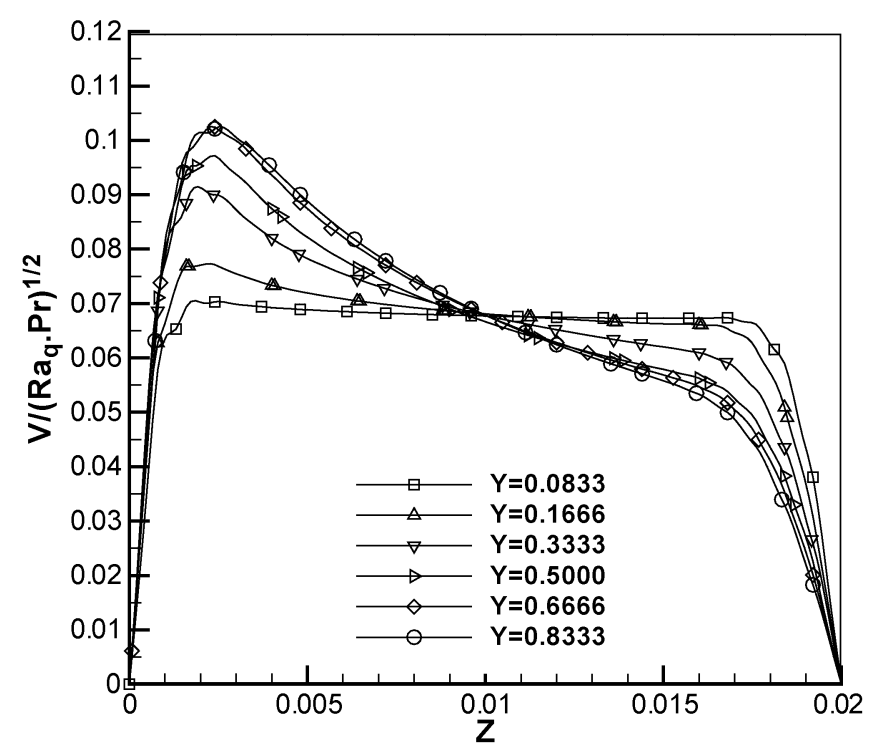

Fig. 8. Velocity profile along the width of channel for the baseline case for the staggered pin fin array with constant inner wall temperature and $\mathrm{Ra}_{\mathrm{T}}=10^{9}$ at $\mathrm{X}=0.0135$.

ditions for chimney flow. For constant temperature boundary conditions on the inner wall, the decomposition in (15) is not useful since $\left(\mathrm{T}-\mathrm{T}_{\mathrm{w}}\right)$ never becomes constant in $\mathrm{y}$, and the buoyancy term never becomes periodic. With this boundary condition, periodicity is achieved only in the trivial sense that the temperature profile becomes invariant with y. Then, the buoyancy term in the momentum equation becomes constant, as does the bulk temperature $\mathrm{T}_{\mathrm{b}}$. Even when $\mathrm{Nu}_{\mathrm{e}}$ is small, no approximately periodic regime is observed.

\section{Local Flow and Temperature Patterns}

For clarity, we consider the constant heat flux boundary conditions to be the baseline; the bulk of the results are presented for this boundary condition, with a few key results for the giventemperature case for contrast. The baseline geometry of $\mathrm{a}=3$, $\mathrm{b}=3, \mathrm{c}=10, \mathrm{E}=0.09$ and $\mathrm{F}=0.009$ is considered.

Figs. 8-10 show corresponding variations of the vertical velocity and dimensionless temperature for constant temperature boundary conditions on the inner wall for $\operatorname{Ra}_{\mathrm{T}}=10^{9}$. Fig. 8 plots the dimensionless velocity $\mathrm{V} /\left(\mathrm{Ra}_{\mathrm{q}} \mathrm{Pr}\right)^{1 / 2}$ versus $\mathrm{Z}$ to facilitate comparison with Fig. 3. For this constant temperature case, $\mathrm{Ra}_{\mathrm{q}}$ is defined in terms of the average inner-wall heat flux obtained posteriori at the constant-temperature boundary. Plotted in this way, the approximate values of the dimensionless vertical velocity for the constant heat flux and temperature cases are seen to be approximately the same. Profiles of the dimensionless temperature $\theta\left(=\left(\mathrm{T}-\mathrm{T}_{\mathrm{i}}\right) /\left(\mathrm{T}_{\mathrm{w}}-\mathrm{T}_{\mathrm{i}}\right)\right)$ versus $\mathrm{Z}$ in Fig. 9 show that flow has not achieved the trivial periodic condition at the panel exit for $\operatorname{Ra}_{\mathrm{T}}=10^{9}$. For $\operatorname{Ra}_{\mathrm{T}}=10^{5}$ (Fig. 10), however, the temperature profiles collapse on each other, suggesting that the bulk temperature has become constant, and that the trivial periodic condition has been reached. Thus, regardless of the inner wall boundary condition, the chimney effect is active in dissipating heat to the fluid if the Rayleigh number is high enough, but is inactive for low Ra.

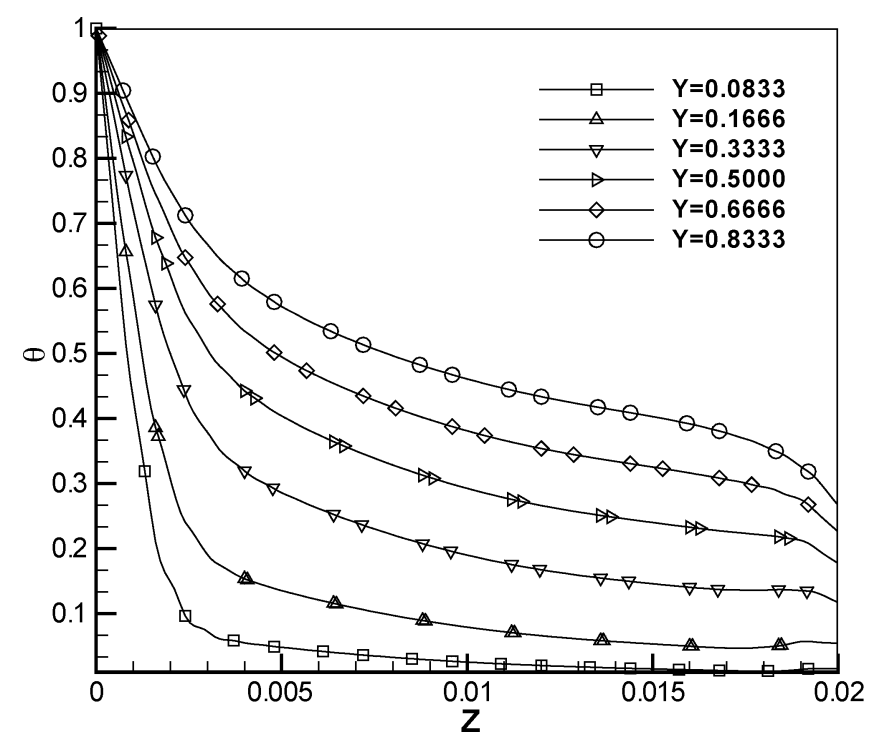

Fig. 9. Dimensionless temperature distribution in fluid along the width of channel for the baseline case for the staggered pin fin array with constant inner wall temperature and $\mathrm{Ra}_{\mathrm{T}}=10^{9}$ at $\mathrm{X}=0.0135$.

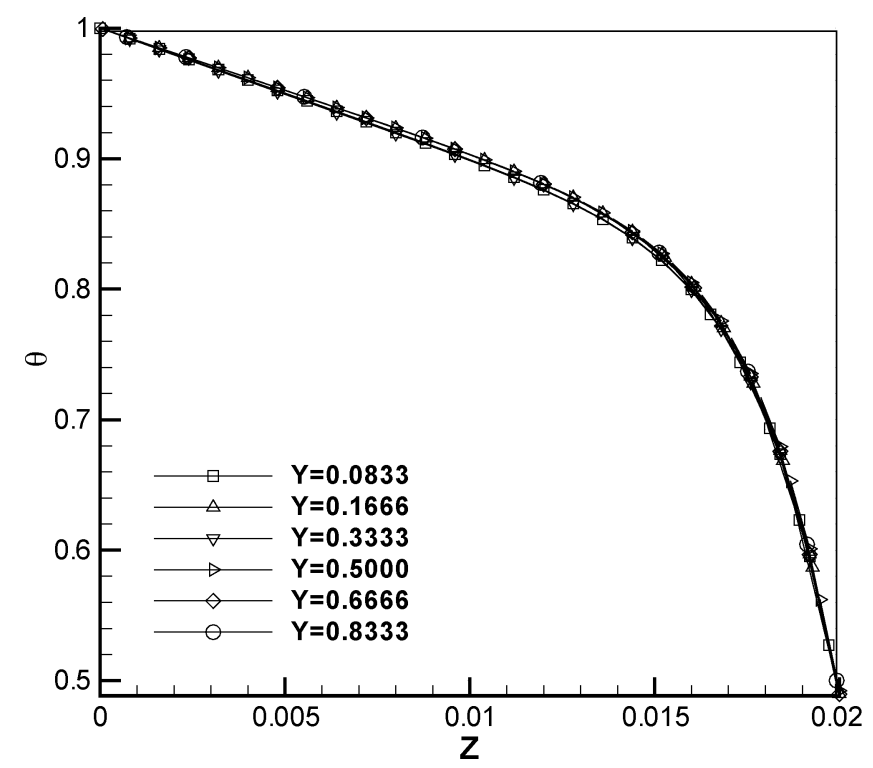

Fig. 10. Dimensionless temperature distribution in fluid along the width of channel for the baseline case for the staggered pin fin array with constant inner wall temperature and $\mathrm{Ra}_{\mathrm{T}}=10^{5}$ at $\mathrm{X}=0.0135$.

\section{Nusselt Number}

The axial distribution of the local Nusselt number for different Rayleigh numbers at the hot wall centerline is shown is Fig. 11 for the constant heat flux case. The local Nusselt number is defined as

$$
N u=\frac{q \cdot \frac{d}{k}}{T_{w}-T_{i}} .
$$

It is evaluated along the hot wall center line drawn from inlet to outlet. The local Nusselt number decreases monotonically from the inlet to outlet of the chimney and approaches the fully developed values for low Rayleigh numbers but not for $\operatorname{Ra}_{\mathrm{q}}>$ 


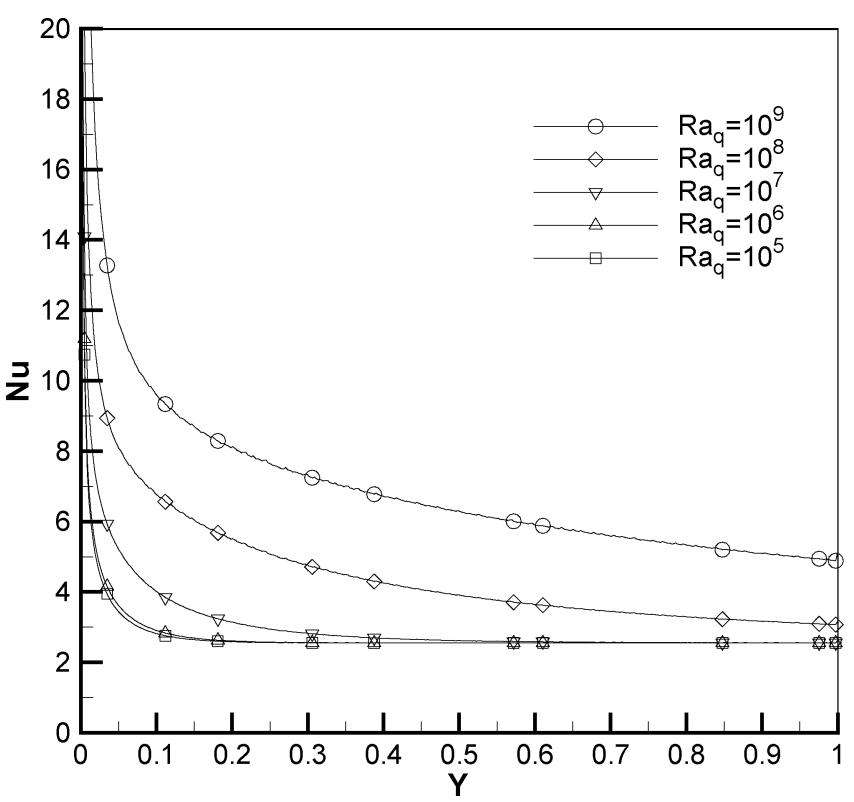

Fig. 11. Local Nusselt number along the chimney height at the hot wall centerline for staggered pin fin array baseline case with constant inner wall heat flux condition $(\mathrm{X}=0.0135, \mathrm{Z}=0)$.

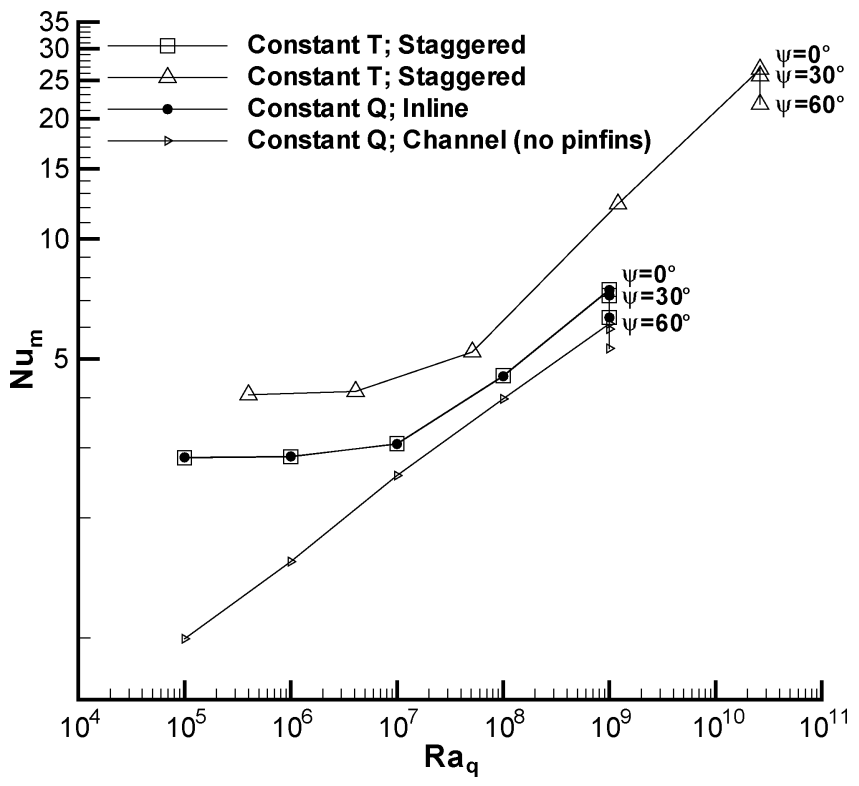

Fig. 12. Variation of the mean Nusselt with $\mathrm{Ra}_{\mathrm{q}}$ for staggered pin fin array baseline case for constant inner wall heat flux condition (inline constant inner wall heat flux results also shown for comparison) and for constant inner wall temperature condition.

$10^{7}$. Thus, for typical lap-top computers at high heat fluxes, the entire height of the back panel is expected to be active.

Fig. 12 shows the variation of mean hot-wall Nusselt number with $\mathrm{Ra}_{\mathrm{q}}$ for both the constant heat flux and the constant wall temperature boundary conditions. The constant temperature results were obtained for $\mathrm{Ra}_{\mathrm{T}}$ between $10^{5}-10^{9}$; the corresponding values of $\mathrm{Ra}_{\mathrm{q}}$ were obtained by evaluating the mean hot-wall heat flux q posteriori. The mean Nusselt number is defined as

$$
N u_{m}=\frac{\frac{q d}{k}}{T_{w m}-T_{i}}
$$

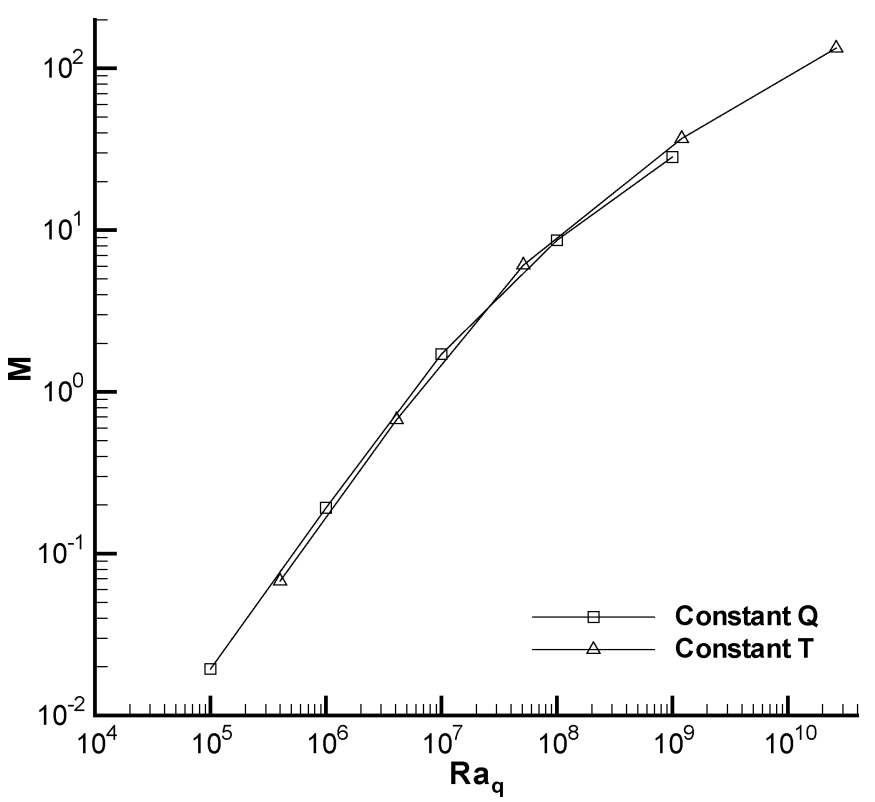

Fig. 13. Dimensionless mass flow rate for different $\mathrm{Ra}_{\mathrm{q}}$ for staggered pin fin array baseline case for constant inner wall heat flux condition and for constant inner wall temperature condition.

where $T_{w m}$ is the mean hot wall temperature, and is equal to $T_{w}$ for the constant temperature case. In general, the mean Nusselt number increases with Rayleigh number as expected. There are differences in the values for the constant flux versus the constant temperature boundary conditions, but the overall trends are similar.

Fig. 13 shows the dimensionless mass flow rate $\mathrm{M}$ induced by the chimney effect for different $\mathrm{Ra}_{\mathrm{q}}$. M increases monotonically with $\mathrm{Ra}_{\mathrm{q}}$ as expected, because the buoyant force induced by longer chimneys is greater than for shorter chimneys. For $\mathrm{Ra}_{\mathrm{q}}<10^{10}, \mathrm{M}$ does not reach an asymptote, reconfirming the fact that the flow is still developing. The two different inner wall boundary conditions yield approximately the same results.

Also shown in Fig. 12 is the variation of the mean Nusselt number for an in-line case with constant inner wall heat flux condition. The geometry corresponds to the baseline case used for the staggered case, with the exception that the pins are in-line. There is virtually no difference between the inline and staggered arrangement for the range of geometry studied here. A comparison with the local velocity profiles and Nusselt numbers in in-line pin-fin study in Jain et al. [8] reveals that in-line and staggered arrays do not yield appreciably different local results. For both cases, the axial space between the fins is a large slow re-circulation zone, with the bulk of the flow occurring between rows of fins.

Fig. 12 also shows the mean Nusselt number versus $\mathrm{Ra}_{\mathrm{q}}$ for a channel flow without pin fins for the baseline case. It can be seen that the increase in Num obtained by adding pin fins is much higher for low Ra than for high Ra. This is because at low Ra, heat transfer is dominated by conduction. Pin fins add surface area thus increasing the heat transfer. The increase in surface area is a small contributor to the overall heat transfer at higher $\mathrm{Ra}$, where convective effects dominate. Indeed, as convection becomes active, pin fins may offer resistance to flow. 


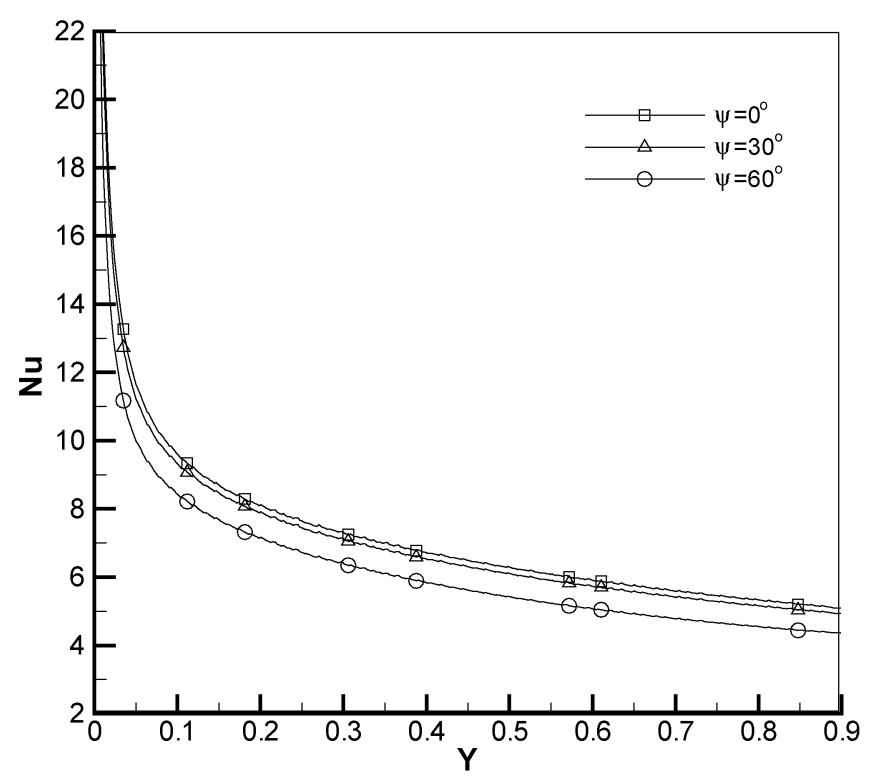

Fig. 14. Local Nusselt number along the chimney length at the hot wall centerline for staggered pin fin baseline case $(X=0.0135, \mathrm{Z}=0)$ for constant inner wall heat flux case and for different inclination angles $\psi$ (of $0^{\circ}$, $30^{\circ}$, and $\left.60^{\circ}\right), \operatorname{Ra}_{\mathrm{q}}=10^{9}$.

Nevertheless there is a $20 \%$ increase in $\mathrm{Nu}_{\mathrm{m}}$ over the fin-less channel even at high Rayleigh numbers.

\section{E. Effect of Panel Inclination}

Fig. 14 shows the effect of display panel inclination on the predicted local hot-wall Nusselt number along the $\mathrm{Y}$ direction for the base line case with $\mathrm{Ra}_{\mathrm{q}}=10^{9}$ for constant heat flux boundary conditions. Variation of $\mathrm{Nu}_{\mathrm{m}}$ inclination for both boundary conditions is shown in Fig. 12. The inclination does not change the predicted Nusselt number substantially, suggesting that buoyancy-driven cooling is workable for normal lap-top usage.

\section{F. Effect of Fin Spacing}

Fig. 15 shows the variation of the mean Nusselt number with porosity. The fin diameter is held constant with $\mathrm{F}=0.009$. Different horizontal spacings (a1-a4) are investigated for a fixed value of vertical spacing, $b=3$. An increase in horizontal spacing decreases frictional resistance, but also decreases the fin area. As a result, an optimum is found, at a porosity of approximately $91 \%$. However the peak is shallow in the range of porosities investigated. This is close to the optimum porosity for forced flow found by Zografos and Sunderland [22], and similar to the minimum found for in-line arrays in Jain et al. [8]. The effect of vertical spacing is studied by varying the vertical spacing (b1-b4) keeping the horizontal spacing constant at $\mathrm{a}=3$. Decreasing the vertical spacing increases the fin area, but there is little increase in resistance since the fins lie within the wakes of upstream fins. As a result, no optimum is found in the vertical spacing. Thermal performance improves monotonically with vertical packing and the primary constraints are likely to be manufacturing-related.

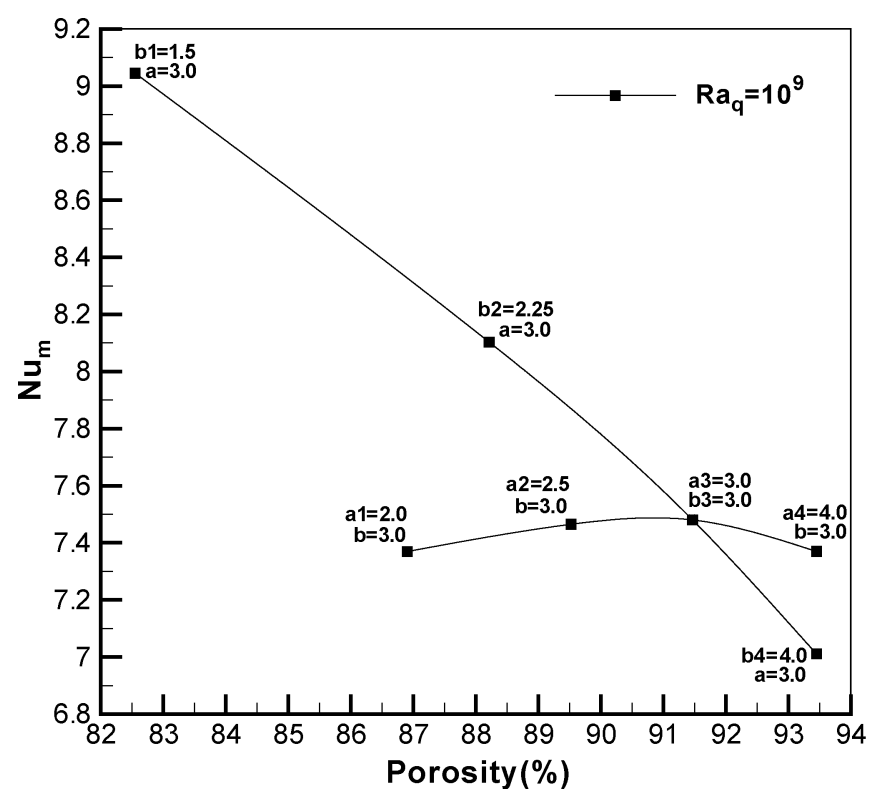

Fig. 15. Mean Nusselt number for different lateral and vertical spacings for staggered pin fin arrangement. (Horizontal spacings "a, a1-a4" and Vertical spacings "b, b1-b4" are as shown).

\section{CONCLUSION}

A numerical study of the use of the chimney effect in cooling the display panels of lap-top computers has been done. Staggered pin-fin arrays in buoyant convection have been considered for both constant heat flux and constant temperature on the inner hot wall. For low heat fluxes, a substantial portion of the display may become thermally inactive because the bulk temperature becomes constant. This is not the case for high heat fluxes; for Rayleigh numbers of $10^{7}$ or greater, the entire display panel is thermally active. For constant flux boundary conditions, a nearly self-similar regime occurs with bulk temperature increasing nearly linearly. For high Rayleigh numbers $(\sim \mathrm{Ra}=$ $10^{9}$ ), approximately two-thirds of the height of the display panel may fall in this regime, and suggests that the chimney effect can be used to advantage. The broad flow behavior for both inner wall boundary conditions is similar provided they are compared on the basis of equal $\mathrm{Ra}_{\mathrm{q}}$. Though there are small variations with respect to the results for in-line pin fins reported in Jain $e t$ $a l$. [8], the overall behavior is similar. As with in-line pin fins, and pin fins in forced flow, studies of fin placement suggest that an optimal porosity for maximum mean Nusselt number is about $91 \%$. The results show that for high enough Ra, chimney cooling using the back panel of the laptop can augment other cooling mechanisms.

\section{REFERENCES}

[1] J. Armstrong and D. Winstanley, "Review of staggered pin fin heat transfer for turbine cooling applications," ASME J. Turbomach., vol. 110, pp. 94-103, 1988.

[2] W. Aung, "Fully developed laminar free convection between vertical plates heated asymmetrically," Int. J. Heat Mass Transfer, vol. 15, pp. 1577-1580, 1972.

[3] — , "Heat transfer in electronic systems with emphasis on asymmetric heating," Bell Syst. Tech. J., vol. 52, pp. 907-925, 1973. 
[4] W. Aung, L. S. Fletcher, and V. Sernas, "Developing laminar free convection between vertical flat plates with asymmetric heating," Int. J. Heat Mass Transfer, vol. 15, pp. 2293-2307, 1972a.

[5] W. Aung, T. J. Kessler, and K. I. Beitin, "Natural convection cooling of electronic cabinets containing arrays of vertical circuit cards," Paper 72-WA/HT 40, ASME, 1972.

[6] - "Free convection cooling of electronic systems," IEEE Trans. Parts Hybrids Packag., vol. PHP-9, pp. 75-86, June 1973.

[7] T. S. Fisher and K. E. Torrance, "Free convection limits for pin-fin cooling," J. Heat Transfer, vol. 120, pp. 633-640, 1998.

[8] A. Jain, D. S. Boyalakuntla, J. Y. Murthy, and C. H. Amon, "Buoyancydriven flow in channels with in-line pin fins," in Proc. 35th Nat. Heat Transfer Conf., Anaheim, CA, 2001.

[9] Y. Jaluria, "Buoyancy-induced flow due to isolated thermal sources on a vertical surface," J. Heat Transfer, vol. 104, pp. 223-227, 1982.

[10] Y. Jaluria and B. Gebhart, "Buoyancy induced flow arising from a line thermal source on an adiabatic vertical surface," Int. J. Heat Mass Transfer, vol. 20, pp. 153-157, 1977.

[11] B. A. Jubran, M. A. Hamdan, and R. M. Abdullah, "Enhanced heat transfer, missing pin and optimization for cylindrical pin fin arrays," ASME J. Heat Transfer, vol. 115, pp. 576-583, 1993.

[12] K. C. Karki and S. V. Patankar, "Cooling of a vertical shrouded fin array by natural convection: a numerical study," J. Heat Transfer, vol. 109, pp. 671-676, 1987.

[13] K. M. Kelkar and D. Choudhury, "Numerical prediction of periodically fully-developed natural convection in a vertical channel with surfacemounted heat generating blocks," Int. J. Heat Mass Transfer, vol. 36, no. 5, pp. 1133-1145, 1993.

[14] S. R. Mathur and J. Y. Murthy, "A pressure-based method for unstructured meshes," Numer. Heat Transfer B: Fundamentals, vol. 31, no. 2, pp. 195-216, 1997.

[15] J. Y. Murthy and S. R. Mathur, "A conservative numerical scheme for the energy equation," J. Heat Transfer, vol. 120, pp. 1081-1085, 1998.

[16] A. Ortega and R. J. Moffatt, "Heat transfer from an array of simulated electronic components: experimental results for free convection with and without a shrouding wall," Heat Transfer Electron. Equip., pp. 5-15, 1985.

[17] _ - "Buoyancy-induced convection in a nonuniformly heated array of cubical elements on a vertical channel wall," Heat Transfer Electron. Equipment, pp. 135-144, 1986.

[18] S. V. Patankar, Numerical Heat Transfer and Fluid Flow. Bristol, PA: Hemisphere, 1980.

[19] G. P. Peterson and A. Ortega, "Thermal control of electronic equipment and devices," Adv. Heat Transfer, vol. 20, pp. 134-181, 1990.

[20] C. M. Rhie and W. L. Chow, "A numerical study of the turbulent flow past an isolated airfoil with trailing edge separation," AIAA J., vol. 21, pp. $1525-1532,1983$

[21] H. Shaukatullah, W. R. Storr, B. J. Hansen, and M. A. Gaynes, "Design and optimization of pin fin heat sinks for low velocity applications," in Proc. SEMI-THERM XII, Austin, TX, 1996, pp. 151-163.

[22] A. I. Zografos and J. E. Sunderland, "Natural convection from pin fin arrays," Exper. Thermal Fluid Sci., vol. 3, no. 4, pp. 440-449, 1990.

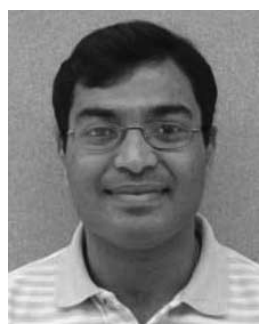

Dhanunjay S. Boyalakuntla received the B.E. degree ( with honors) in mechanical engineering from the Birla Institute of Technology and Science, India, in 1998 and the M.S. degree in mechanical engineering from Carnegie Mellon University, Pittsburg, PA, in 2000 where he is currently pursuing the Ph.D. degree in mechanical engineering.

His field of interest is computational fluid dynamics and heat transfer, electronics cooling and granular flows. He has worked on hierarchical compact model development for simulation of electronic packages. He is currently working on the modeling and simulation of granular flows using discrete element methods.

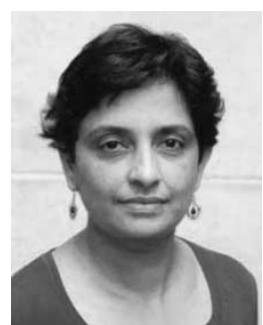

Jayathi Y. Murthy received the Ph.D. degree from the Department of Mechanical Engineering, University of Minnesota, Minneapolis, in 1984.

She has worked in both academia and industry. She spent over ten years at Fluent, Inc. (a leading developer and vendor of computational fluid dynamics software). She moved to Carnegie Mellon University, Pittsburgh, PA, in 1998 as an Associate Professor in the Department of Mechanical Engineering. She subsequently moved to Purdue University, West Lafayette, IN, in 2001, as a Professor in the School of Mechanical Engineering. Her research interests lie in the computational heat transfer and fluid mechanics. Over the last few years, she has focused on the development of unstructured, solution-adaptive finite volume methods for industrial applications. Since returning to academia, her work has focused on the analysis of micromanufacturing processes, direct simulations of multi-phase flows, and more recently, on developing models and solution techniques for sub-micron heat transfer. She has also been working in the area of electronics thermal management, particularly on the development of model reduction techniques for fast system-level simulations. She is the author of over 100 technical papers and reports, two book chapters on numerical methods, and has edited two volumes on heat transfer and CFD.

Dr. Murthy serves on the K-16 and K-20 Committees of the ASME.

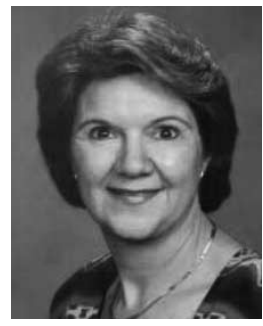

Cristina H. Amon (F'02) received the Ph.D. degree in mechanical engineering from Simon Bolivar University, Venezuela, in 1981.

She is a Professor in the Department of Mechanical Engineering and holds a joint appointment in Biomedical Engineering. She joined Carnegie Mellon University in 1988 where she is currently the Raymond J. Lane Distinguished Professor of Mechanical Engineering and Director of the Institute for Complex Engineered Systems (ICES), a strategic initiative of the College of Engineering for pursuing multidisciplinary research on complex systems. She has contributed six book chapters, one McGraw Hill Custom Textbook, and over 140 refereed articles in education and research literature. Her research pioneered the development of Computational Fluid Dynamics (CFD) for formulating and solving thermal design problems subject to multidisciplinary competing constraints. This led to her creation of a multistage concurrent thermal design methodology based on hierarchical model refinement, which combines CFD, nondeterministic experiments and Bayesian statistics. She has also made seminal contributions on self-sustained oscillatory flows and thermal management of electronics, elucidating flow destabilization mechanisms which induce heat transfer enhancement with chaotic mixing; quantifying conjugate time-dependent effects in electronic packages with multilength and time scales; and developing on-demand recuperative transient thermal management technologies for portable electronics.

Dr. Amon received the Distinguished Engineering Educator award from the SWE in 1999, the Professor of the Year award from the SWE in 2000, the Gustus L. Larson Memorial Award for outstanding achievements in mechanical engineering from the ASME, the Engineer of the Year Award from the Pittsburgh Chapter, ASME in 1999, several awards from the American Society for Engineering Education (ASEE), the George Westinghouse Award in 1997, and the Ralph Coats Roe Award in 2002. She is a Fellow of ASME. 